DOI: 10.20472/IAC.2017.031.020

DEYUAN HE

Universiti Brunei Darussalam, Brunei Darussalam

QUNYING ZHANG

Universiti Brunei Darussalam, Brunei Darussalam

\title{
UNIVERSITY TEACHERS' AND STUDENTS' UNDERSTANDING OF LEARNING A FOREIGN LANGUAGE: COPING WITH SPEAKING ANXIETY
}

\begin{abstract}
:
China is well known for its very large number of English learners, but most of them have suffered from foreign language speaking anxiety (FLSA) when expressing themselves orally in the language. FLSA has been scarcely addressed in the educational settings of China, especially in terms of the practical strategies for reducing students' FLSA. In light of this gap, an investigation into the coping strategies for FLSA was conducted by drawing comprehensive data from 302 university students and 30 teachers of English at two universities in different parts of China. Questionnaire surveys and focused interviews were adopted to collect data and explore perceptions concerning FLSA. With these two cross-validated research methods, 32 strategies for reducing students' FLSA were identified. These strategies were verified to be effective after being applied for a period of four months by the participants. The results of the study showed that persistent application of such strategies is of great significance in alleviating students' FLSA and hence making their learning more enjoyable. The results and findings were also discussed in relation to those from previous research in the field. Furthermore, the strategies verified in this study would provide important pedagogic implications for foreign language education involving English.
\end{abstract}

\section{Keywords:}

speaking anxiety; coping strategies; university students; effectiveness; China 


\section{Introduction}

With English being an international language, bilingual education (Chinese and English) has been promoted in China for about two decades, and English has become a required subject from Primary 3 (8-9 years old) till post-graduate level in China for more than one decade. In this background, Chinese-English bilingual speakers have increased dramatically over the years (He, 2015; He \& Zhang, 2010). Although the exact number of such bilinguals is unavailable, the magnitude of English learners in China may be a good indication. Statistics show that there were more than 190.96 million students receiving formal classroom English instruction in the country in 2013 (Ministry of Education 2014). In addition, bilingual education is supposed to play a key role in the development and reform of the national education system (e.g. the internationalization of education) according to The Guideline for National Educational Reform and Development for the Period of 2010-2020.

Given the importance attached to the English language, learning English, However, can be an anxiety-provoking experience (Onwuegbuzie, Bailey, and Daley 1999). In reality, Chinese students' overall learning effectiveness in EFL courses is less-thansatisfactory, especially in terms of their spoken English. There are many reasons for the gap between the quantity of instruction and the results achieved, and foreign language speaking anxiety (FLSA) is believed to be a prominent one (He 2013; Maclntyre, Noels, and Clément 1997). Therefore, the investigation of FLSA is of significance, especially for non-English majors who usually have insufficient opportunities to speak the target language in their everyday life. By focusing on Chinese non-English-major students, this study endeavours to identify and verify the effective strategies that help reduce their FLSA, hence enhancing their learning effectiveness.

\section{Studies on anxiety and language learning}

Issues concerning anxiety in language learning have been widely discussed for at least fifty years (e.g. Alpert and Haber 1960; Dewaele 2013; Horwitz, Horwitz, and Cope 1986). Anxiety is defined as the subjective feeling of tension, apprehension, nervousness, and worry associated with an arousal of the automatic nervous system (Spielberger 1983). Foreign language anxiety (FLA) is fear or apprehension occurring when a learner is expected to perform in a second or foreign language (Gardner and Maclntyre 1993). Horwitz et al. (1986) concluded that FLA frequently shows up in listening and speaking activities, testing situations, overstudying, certain beliefs (for instance, everything that will be said in a foreign language should be correct), and so on. A number of recent studies have quantified the effects of FLA on foreign language learning (e.g. Dewaele 2013; Liu and Jackson 2008). Although different methods have been employed, self-reported questionnaire is an appropriate means to examine anxiety in learners (Horwitz et al. 1986). 


\section{Studies on the strategies for FLSA}

Many studies have explored the reasons resulting in adult learners' FLA in general (e.g. Alrabai 2014a; He 2013; Liu and Jackson 2008; Shabani 2012; Yan and Horwitz 2008). Nevertheless, studies concerning the strategies for FLA, especially FLSA, are insufficient. The few notable ones will be reviewed in this section. Lucas (1984) mentioned two steps to manage students' FLSA in Japan. Her first step, to create a warm and easy-going classroom atmosphere, includes the following methods: to provide students with relaxation exercises (e.g. rhythmic breathing), to help students become familiar with one another at the outset of a course, to introduce students to social formulae and dialogues, to teach students how to get out of trouble or embarrassing situations, and to teach students to use gambits (e.g. really? Uh-huh) appropriately. Her second step is to involve students in various classroom activities so that students can practise more in the target language. However, like most of the other studies on coping strategies for FLSA, hers did not mention whether these methods or strategies have been verified to be effective or not.

Another study based on empirical data from 244 students learning Spanish in the USA found that teacher characteristics such as 'a non-harsh attitude towards error correction, a positive, friendly and relaxed general attitude towards students' can help alleviate students' FLSA (Young 1990, p. 551). Through her interviews with four language specialists, Young (1992) identified 16 strategies coping with FLSA, including having students work in pairs or small groups, not forcing students to speak before they are ready, and not putting anyone on the spot.

Donley (1997) proposed ten coping strategies, such as discussing feelings with peer students and the instructor, getting prepared for class, and remembering that making errors is natural for language learning. However, all the ten methods are simply his own critical thoughts based on his personal Spanish teaching experiences in the USA, rather than findings from an empirical study.

Kondo and Yang (2004) found 70 tactics for coping with language anxiety based on their study about 219 students learning EFL in Japan, which were cohered into five categories: preparation, relaxation, positive thinking, peer thinking, and resignation (i.e. students doing nothing to reduce their FLA, e.g. giving up, sleeping in class). Nonetheless, it should not be ignored that resignation is not an active coping strategy and hence of no pedagogic value.

Liu (2007, p. 132) listed ten reasons of non-English majors' FLSA in China, but her participants 'seemed to be at a loss' when asked about the strategies for coping with their FLSA. Only a couple of them suggested that students should have more practice and build up self-confidence, and teachers should try to provide a 'friendly, supportive and non-threatening classroom-learning environment'. Nevertheless, Liu's (2007) study was based on a sample with only 27 students.

Hashemi and Abbasi (2013) reviewed and summarised previous studies and listed 
twenty coping strategies for EFL instructors and learners, to name a few, instructors acknowledging the existence of anxiety among learners, instructors using formative assessment more to decrease learners' worry about classroom performance and grades, learners using positive self-talk, and learners encouraging themselves to take risks in EFL learning.

Among the studies focusing on strategies, Alrabai (2014b) is the only one that tested the effectiveness of the strategies in EFL classes. He proposed and tested seven strategies for teachers to implement, including demonstrating appropriate teaching behaviour to students, decreasing students' communication apprehension, decreasing students' fear of negative evaluation, among others. Each strategy involves specific practices and techniques that facilitate teachers' implementation of the strategy. However, the participants in his study are of varied EFL proficiency levels from beginners to advanced learners in Saudi Arabia context, which may lead to a doubt whether the same strategies can be applicable to learners of different EFL levels.

\section{Research question}

From the studies mentioned above, it can be concluded that there are fewer empirical studies focusing on the coping strategies for FLSA than the ones on the reasons leading to FLSA, and few of the existing ones proved whether the strategies they reported were effective or not except Alrabai (2014b). In addition, some of these strategies may be inappropriate to bilingual students in China. The paucity of empirical research into FLSA of university students in China also makes it more significant to make such an attempt. Specifically, the research question this article endeavours to address is: What strategies do Chinese bilingual university students and their English teachers believe are effective in coping with FLSA?

\section{Method}

\section{Participants}

302 bilingual students and 30 teachers from two universities in China took part in the questionnaire survey, and 30 students and three teachers among them were also interviewed. In order to make the sample more representative, the author endeavoured to involve teachers and students from two universities of different academic levels and geographic regions, one key university in south-central China and one second-tier university in eastern China, and they take students from all over the country. NonEnglish majors and their English teachers were selected as participants because nonEnglish majors constitute the majority of bilingual speakers in China and their views would be typical in the issues addressed in this research.

All the students were native Chinese, aged from 17 to $23(M=19.9)$. Of them, 168 (55.6\%) were male and $134(44.4 \%)$ female. They were from four disciplines: Engineering (156, 51.7\%), Business (77, 25.5\%), Arts (36, 11.9\%), and Science (33, 
$10.9 \%)$.

As another stakeholder providing independent perspectives, teachers were also included in the research. Among them, 11 (36.7\%) were male and 19 (63.3\%) female. They were aged between 23 and $50(\mathrm{M}=36.4)$, and their English teaching experience ranged from two months to 27 years $(M=12.6)$. With regard to academic rank, four $(13.3 \%)$ of them were instructors, 16 (53.3\%) lecturers, eight (26.7\%) associate professors, and two (6.7\%) professors.

\section{Application and verification of the strategies found}

The study comprises two stages. The first stage was the main data collection including surveys with two questionnaires and focused interviews. Questionnaire I (see Appendix I) from He (2013) was used to test students' FLSA level and Questionnaire II (see Table 1) was to identify the strategies for coping with FLSA. On the basis of preliminary data analysis, some strategies that were believed to be helpful in reducing students' FLSA were identified. The second stage of the study was undertaken two months later. First of all, 60 of the questionnaire participants with high level of anxiety were selected judging from their scores of Questionnaire I. They were from four classes at two universities (two classes from each). Half of them were set as the experimental groups (one group from each university) while the other half were used as control groups (ibid). Secondly, students in the experimental groups were instructed the specific strategies and asked to apply them in their daily English learning under their teacher's guidance; and their teacher applied the related strategies as well. Then four months later, these 60 students were asked to take the same survey again with Questionnaire I and six of them and two teachers were interviewed so as to examine the effectiveness of the strategies.

\section{Instruments and analyses}

This research adopted both questionnaire surveys and focused interviews to crossvalidate the data sources. Another purpose of the interviews was to seek new possible strategies for FLSA in addition to the data from Questionnaire II.

Questionnaire survey. Both questionnaires used five-point Likert scales, which were respectively developed to examine students' FLSA level and to identify the strategies for coping with their FLSA. These new affective instruments were constructed according to the guidelines of DeVellis (1991) and Gable and Wolf (1993). Firstly, a thorough review of previous literature on FLA was performed. Secondly, three university students were pilot interviewed and they provided FLSA coping strategies they once applied in their English learning. Thirdly, the statements derived from the first two steps were refined in line with the 19 well-accepted principles (cf. Brown and Rodgers 2002, p. 143). For example, overly long items, unclear or ambiguous items, negative items, and incomplete items should be avoided in writing a good survey questionnaire. 
The two newly-developed questionnaires were piloted with 30 bilingual students and 3 of their English teachers at a Chinese university. The pilot data yielded Cronbach's alpha coefficients of .86 and .88 for Questionnaires I and II respectively, which indicated that the instruments were robust and reliable.

Focused interview. Focused interviews were used in both Stage I and Stage II. In Stage I, 15 male and 15 female student questionnaire participants and three of the teachers were interviewed, and six student participants and two teachers were interviewed in Stage II. The interviews were conducted in Chinese, either in groups (for students) or individually (for teachers). The interview data were coded using qualitative data analysis software, MaxQDA.

\section{Results and findings}

\section{Stage I- questionnaire survey}

Questionnaire I was designed to examine students' FLSA level, which included 13 fivepoint Likert scale items, so theoretically their anxiety scores should range from 13 to 65 with 39 as the median. The mean score $(M=45.76, S D=4.08)$ of Questionnaire I indicated that, overall, these students had a comparatively high level of FLSA (cf. Kim 2000).

For the results of Questionnaire II, which contains 12 items pertaining to FLSA coping strategies, both students and their English teachers supported all the items. Table 1 displays their support in terms of response frequencies and means. In other words, all 12 strategies were believed by the participants to be useful in reducing FLSA.

Table 1. Response frequencies and means of the items of Questionnaire II $(\mathrm{N}=332)$.

\begin{tabular}{|c|c|c|c|c|c|c|}
\hline Items & $\begin{array}{l}\text { SD } \\
(\%)\end{array}$ & $\begin{array}{l}D \\
(\%)\end{array}$ & $\begin{array}{l}N \\
(\%)\end{array}$ & $\begin{array}{l}A \\
(\%)\end{array}$ & $\begin{array}{l}\text { SA } \\
(\%)\end{array}$ & Means \\
\hline $\begin{array}{l}\text { 1. Having classmates work in small groups helps reduce my } \\
\text { nervousness when speaking a FL. }\end{array}$ & 0.6 & 9.0 & 19.6 & 64.5 & 6.4 & 3.67 \\
\hline $\begin{array}{l}\text { 2. It helps reduce my nervousness to talk with other students } \\
\text { about the fears in speaking a FL. }\end{array}$ & 0.6 & 12.3 & 30.1 & 51.9 & 5.1 & 3.48 \\
\hline $\begin{array}{l}\text { 3. Participating in a supporting group or activity (e.g. a FL } \\
\text { corner) helps reduce my fears in speaking that language. }\end{array}$ & 0.9 & 9.0 & 29.8 & 52.1 & 8.2 & 3.57 \\
\hline $\begin{array}{l}\text { 4. Doing relaxation exercises (e.g. productive self-talk) helps } \\
\text { reduce my fears in speaking that language. }\end{array}$ & 0.3 & 5.1 & 27.4 & 60.2 & 6.9 & 3.69 \\
\hline $\begin{array}{l}\text { 5. If accuracy is not the focus, I will not be so nervous about } \\
\text { speaking a FL. }\end{array}$ & 0.6 & 4.2 & 17.5 & 70.8 & 7.0 & 3.79 \\
\hline $\begin{array}{l}\text { 6. I do not feel so anxious when speaking a FL in a friendly } \\
\text { environment. }\end{array}$ & 0.6 & 4.2 & 10.9 & 72.0 & 12.4 & 3.92 \\
\hline $\begin{array}{l}\text { 7. Teachers' encouragement makes me feel relaxed when } \\
\text { speaking a FL. }\end{array}$ & 0.0 & 4.6 & 20.8 & 64.2 & 10.5 & 3.80 \\
\hline $\begin{array}{l}\text { 8. A humourous teacher helps reduce my nervousness in } \\
\text { speaking a FL. }\end{array}$ & 0.0 & 2.7 & 7.5 & 72.9 & $\begin{array}{c}16 . \\
8\end{array}$ & 4.04 \\
\hline
\end{tabular}




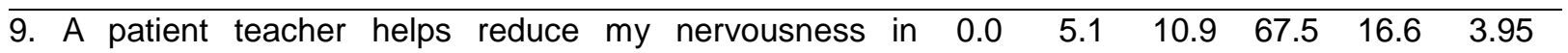
speaking a FL.

10. I feel relaxed about speaking a FL if I know that mistakes $\begin{array}{lllllll}0.6 & 7.5 & 20.8 & 60.0 & 11.2 & 3.74\end{array}$ are part of the language learning process and made by everyone.

11. I feel relieved about speaking a FL if my teacher corrects my mistakes indirectly (e.g. just repeat the right form instead of saying that I am wrong).

12. Playing language games helps reduce my nervousness in speaking a FL.

Notes: 1. SD: strongly disagree; D: disagree; N: neither disagree nor agree; A: agree; SA: strongly agree.

2. The percentages have been rounded to one digit after the decimal point; the means have been rounded to two digits after the decimal point. 


\section{Stage I- focused interview}

On the whole, the findings of the interviews are generally consistent with those of the questionnaire data. When students were asked what strategies may help reduce their anxiety in speaking a FL, they reported the following (arranged in decreasing order of mentions):

- Strategies concerning FL teachers' personal characteristics and behaviours;

- Strategies concerning error correction;

- Creating relaxed or friendly atmosphere;

- Trying to use a FL more;

- Reducing the fear in making mistakes;

- Trying to remind oneself to relax;

- Preparing well;

- Using more body language;

- Overcoming the reasons leading to anxiety;

- Being brave to speak a FL;

- Trying to use simple words;

- Watching some real life TV programmes in a FL.

The first two strategies cover a good many subsets, which will be explained separately later. Most of these strategies, except the last one, were mentioned by more than one student. The following are two examples given by student informants.

I agree, in a relaxed environment, we won't worry about making mistakes, and the teachers also encourage us to speak English. (Example 1)

I tried to get myself less anxious at speaking English by making myself more familiar with this language, for example, speak English whenever possible, sometimes even think aloud in English, and watch a lot of English movies. (Example 2)

Like the students, the teachers also emphasised the importance of creating a friendly or relaxed atmosphere for students to speak a FL, and they added other two strategies they used to manage students' FLSA in their teaching practices: arrange some games in English and provide examples before oral tasks. Below is one response from a teacher:

I try to arrange some games in English in classroom that may help them to relax. I also provide them with some examples before an oral task so that they can learn to finish the task by imitating. (Example 3)

Strategies concerning FL teachers' personal characteristics and behaviours. FL 
instructors' personalities are another important factor that is argued to be helpful in reducing students' FLSA (e.g. Young 1992). The interview data from the students revealed that $\mathrm{FL}$ teachers with the following personal characteristics and behaviours can help decrease students' FLSA (in decreasing order of mentions):

- Friendly;

- Humourous;

- Knowledgeable;

- Good at enhancing students' interest in a FL;

- Good at employing different teaching strategies;

- Patient;

- Lively;

- Good at creating conducive learning environment;

- Modern (instead of being reserved);

- Outgoing;

- Versatile;

- Sensitive to cultural differences;

- Excluding students' classroom performance from final assessment;

- Learning some teaching styles from native-speaking English teachers.

Among the 14 features, the first eight were mentioned by more than half of the students, especially the first two, emphasised by nearly all the students. There was only one mention of the last two features. Below is one typical citation:

English teachers should be humourous and be equipped with broad knowledge, such as knowledge about sports, entertainments, and arts. (Example 4)

The teachers repeated three features in the above list (i.e. friendly, humourous, patient), and they added a new one (i.e. easy-going).

Strategies concerning error correction. It is believed that the way of error correction is closely related to students' FLSA (Gregersen 2003; Gregersen and Horwitz 2002), so the interviewees were asked specifically about the way they preferred their errors to be corrected (for students) or the way they preferred to correct their students' errors (for teachers). When the students were asked whether they would correct students' oral English errors if they were teachers, more than half (19) of them gave a negative answer unless when there was an error causing problems of intelligibility (see Example 5). One important reason for them to ignore errors was because they believed it was either discouraging to students or impractical to correct all the errors students made. Nonetheless, there were still six students insisting that teachers should correct students' 
errors (see Example 6) and five students did not answer this question.

I would not correct them. Instead, I would introduce them some good websites that can help those who want to correct their mistakes. Besides, I think it is impractical for the teacher to correct students' mistakes one by one. (Example 5)

I would, I believe this will help improve his/her English. (Example 6)

When it is necessary to correct errors, most of the students (22) would prefer to correct them indirectly if they were teachers (see Example 7), only seven of them chose to correct errors directly (see Example 8):

I think teachers should pay attention to the way of error correction. If I were a teacher, I would just repeat the right expressions. In this way, I think they will realise that what they said is not correct. (Example 7)

After they finish speaking, I would praise them first, and then I would tell what is wrong and then tell the right one, which may give them stronger impression of the error and help them avoid it next time. (Example 8)

Concerning when is the appropriate time for error correction - in or after class, students were somewhat equally distributed in terms of responses: nine of them thought that it depended on different situations, for instance, size of the class and number of errors (see Example 9); while eight and seven of them argued for 'after class' (see Example 10) and 'in class' (see Example 11) respectively; and six offered no response. The reasons put forward by students for correcting errors 'after class' include protecting students' self-esteem, saving teaching time, and keeping the fluidity of classroom teaching, among others. The reasons for them choosing 'in class' are, to name a few, that students still have fresh impression of their errors, that students might get uneasy being corrected individually after class, and that teachers may forget to correct the errors after class.

It depends. If it is a small class, I may correct it after class privately. If it is a big class, then correcting it in a polite and acceptable way may also help other students who may make the same mistake. (Example 9)

I will do so after class, since I think this is good for their confidence. (Example 10)

I think it will be better to correct it in class, since it will make me more nervous if I am corrected individually after class. Besides, I may forget what kind of mistakes I made in class, and so the effect of the error correction might be reduced. (Example 11)

As for the above three questions - whether, how, and when - concerning error 
correction, the real teachers, unlike the 'imaginary teachers' (the students interviewed), agreed that they usually did not correct their students' errors; if it was really necessary to do so, they preferred the indirect way by just repeating the right; and they argued that the right time for error correction was dependent on the factors like features of errors (e.g. common or not), availability of instruction time, the personality of individual student (e.g. self-conscious or not). Below is a representative example:

Generally, I do not correct their mistakes unless it is a quite serious and common one. When I did correct their mistakes, I usually just repeated the right. Besides, if the mistakes are quite common, I usually correct them in classroom, or else, I prefer to correct them after class. (Example 12)

The first stage of the study yielded 32 FLSA coping strategies (see Appendix II for the list of the strategies), including all the strategies as shown in Table I and those elicited from the interviewees. These strategies were applied and verified in the second stage.

\section{Stage II - application and verification of the strategies found}

Selection of participants for Stage II. As mentioned earlier, in order to apply and verify the effectiveness of the strategies identified in Stage I, 60 students with high level of FLSA were selected out of the participants and were invited to take part in Stage II of the study. All the 60 students were those with anxiety scores above 47 , which is the cutoff point of the one third students who obtained high anxiety scores among the 302 student participants for Questionnaire I. The 60 students were distributed almost evenly in gender with 31 being females and 29 males. In each university, the participants were divided equally into two groups - the experimental group in one class and the control group in another. The effectiveness of the strategies was assessed by comparing the questionnaire scores obtained from the two groups in Stage I and Stage II.

Before applying the strategies found in Stage I, the author contacted (via phone calls and emails) two of the English teachers who helped with data collection in Stage I at the two universities, and provided them with detailed explanations of the 32 coping strategies.

All the strategies that might cause doubts and confusions to teachers and students were fully discussed between the two teachers and the author. Each of the two teachers was teaching two classes of the same school year. The pre-selected experimental groups were from one class and the control groups from the other. Then they were asked to explain the strategies identified to the students in the experimental classes and guide them to use the strategies in daily English learning. The teachers themselves were also encouraged to apply the strategies directed to teachers in the experimental classes. For example, teachers were suggested to pay attention to when and how to correct students' spoken errors and to adopt appropriate error correction strategies 
consciously.

In the following four months, the author kept frequent contacts by emails, telephones, and Skype with the two teachers (at least once a week) and the students in the experimental groups (once a week with different students) to make sure that they were really using the strategies introduced and that their questions arising from applying the strategies were well addressed. Moreover, the author observed each of the experimental classes twice and found the teachers and students applied the strategies efficiently and persistently. For instance, both of the teachers took the initiative to organise as many language activities as possible in small groups, and the students confirmed after class that their teacher organised more group discussions recently, which they believed was helpful in alleviating their FLSA. Meanwhile, the control classes were taught as usual without applying any of the strategies consciously. Appendix III is a log taken while observing a 50-minute class on Doing Business Online. The class consisted of 56 students. The teacher used ten of the anxiety coping strategies as underlined in Appendix III.

Four months after the application of these strategies, the 60 students were invited to answer Questionnaire I again. In addition, six students from the experimental groups and their teachers were interviewed for more qualitative data.

Participants' anxiety score differences across two stages. MANOVA was used to compare the participants' mean differences before and after applying the strategies with 'stage' (Stage I vs. Stage II) as fixed factor and the participants' anxiety scores as dependent variables. The hypothesis behind the verification of the strategies in Stage II is that successful application of these strategies by students and teachers in the experimental groups will lower students' FLSA level and then make the reasons included in Questionnaire I less prominent in contributing to students' FLSA. In other words, the experimental groups' mean scores on Questionnaire I in Stage II are supposed to decrease (preferably significantly) while those of the control groups remain more or less the same. From Table 2, it can be seen that the participants in the experimental groups demonstrated a significantly decreasing tendency in anxiety scores.

In the experimental groups, 26 participants demonstrated decreased scores on Questionnaire I with 18 statistically significant decreases, while only three increases were found but none of them being significant and one mean remained the same across stages. Meanwhile, in the control groups, only one participant showed significant decrease in Stage II, two remained the same and one increased remarkably, and the other 26 either increased or decreased without statistical significance.

Table 2. Participants' FLSA mean differences across two stages.

\begin{tabular}{|c|c|c|c|}
\hline Participant No. & Stage I / Stage II & Participant No. & Stage I / Stage II \\
\hline Experimental Group & & Control Group & \\
\hline 1 & $3.86 / 2.24^{* *} \downarrow$ & 138 & $3.75 / 3.37$ \\
\hline
\end{tabular}




\begin{tabular}{|c|c|c|c|c|c|}
\hline 18 & $4.18 / 2.89^{* \star}$ & $\downarrow$ & 139 & $3.69 / 3.69$ & --- \\
\hline 20 & $3.81 / 2.71^{*}$ & $\downarrow$ & 152 & $4.15 / 3.90$ & $\downarrow$ \\
\hline 37 & $3.81 / 2.94$ & $\downarrow$ & 154 & $3.97 / 3.64$ & $\downarrow$ \\
\hline 68 & $3.73 / 2.37^{* *}$ & $\downarrow$ & 155 & $3.76 / 3.87$ & $\uparrow$ \\
\hline 69 & $3.71 / 2.92$ & $\downarrow$ & 166 & $3.82 / 3.58$ & $\downarrow$ \\
\hline 70 & $3.64 / 2.81$ & $\downarrow$ & 170 & $3.65 / 3.36$ & $\downarrow$ \\
\hline 77 & $3.83 / 2.77^{*}$ & $\downarrow$ & 177 & $3.69 / 2.71^{*}$ & $\downarrow$ \\
\hline 81 & $3.79 / 2.59^{*}$ & $\downarrow$ & 182 & $3.75 / 3.44$ & $\downarrow$ \\
\hline 84 & $3.63 / 2.61^{*}$ & $\downarrow$ & 184 & $3.65 / 3.65$ & -- \\
\hline 88 & $3.63 / 3.63$ & --- & 185 & $3.71 / 3.35$ & $\downarrow$ \\
\hline 91 & $3.78 / 2.59^{*}$ & $\downarrow$ & 187 & $3.77 / 3.32$ & $\downarrow$ \\
\hline 96 & $3.67 / 2.65^{\star}$ & $\downarrow$ & 189 & $3.79 / 3.40$ & $\downarrow$ \\
\hline 97 & $3.65 / 3.94$ & $\uparrow$ & 191 & $3.73 / 3.54$ & $\downarrow$ \\
\hline 100 & $3.79 / 3.82$ & $\uparrow$ & 193 & $3.73 / 4.85^{* *}$ & $\uparrow$ \\
\hline 106 & $3.69 / 2.53^{*}$ & $\downarrow$ & 194 & $3.68 / 3.99$ & $\uparrow$ \\
\hline 112 & $3.79 / 2.92$ & $\downarrow$ & 197 & $3.69 / 3.40$ & $\downarrow$ \\
\hline 113 & $3.69 / 2.41^{*}$ & $\downarrow$ & 198 & $3.69 / 3.52$ & $\downarrow$ \\
\hline 120 & $3.79 / 2.98$ & $\downarrow$ & 207 & $3.77 / 3.98$ & $\uparrow$ \\
\hline 121 & $3.69 / 3.71$ & $\uparrow$ & 208 & $3.65 / 3.36$ & $\downarrow$ \\
\hline 130 & $3.75 / 2.72^{*}$ & $\downarrow$ & 211 & $4.03 / 4.25$ & $\uparrow$ \\
\hline 224 & $3.67 / 3.06$ & $\downarrow$ & 277 & $3.65 / 3.35$ & $\downarrow$ \\
\hline 230 & $3.75 / 2.68^{*}$ & $\downarrow$ & 278 & $3.71 / 3.48$ & $\downarrow$ \\
\hline 246 & $3.65 / 2.94$ & $\downarrow$ & 280 & $3.65 / 4.00$ & $\uparrow$ \\
\hline 247 & $3.97 / 2.53^{\star *}$ & $\downarrow$ & 294 & $3.71 / 3.41$ & $\downarrow$ \\
\hline 249 & $3.76 / 2.94^{*}$ & $\downarrow$ & 295 & $3.63 / 3.44$ & $\downarrow$ \\
\hline 250 & $3.67 / 2.82$ & $\downarrow$ & 296 & $3.69 / 3.49$ & $\downarrow$ \\
\hline 251 & $4.05 / 3.10^{*}$ & $\downarrow$ & 298 & $3.67 / 3.54$ & $\downarrow$ \\
\hline 262 & $3.75 / 2.94^{*}$ & $\downarrow$ & 301 & $3.88 / 3.65$ & $\downarrow$ \\
\hline 269 & $3.67 / 2.71^{*}$ & $\downarrow$ & 302 & $3.66 / 3.27$ & $\downarrow$ \\
\hline
\end{tabular}

Interview responses in Stage II. Six students from experimental groups (three males and three females) and two teachers were interviewed in Stage II. They were asked about their perceptions of the effectiveness of the strategies. Five of the student interviewees demonstrated significantly lower anxiety scores in Stage II while the last one showed no remarkable change.

The interview findings were in accordance with the quantitative results. Seven of the eight interviewees believed that the strategies they applied in English learning or teaching were effective in reducing their (or their students') FLSA (as shown by Example 13). Only the one who demonstrated no significant change in anxiety scores in Stage II reported that she found these strategies might not be useful to her, and she attributed this to her anxious personality (see Example 14).

On the whole, I think the strategies you told me were quite effective, I feel I become less anxious while speaking English now, both in and out of classroom. Thank you, I think I will keep on trying them. (Example 13) 
I tried the strategies. However, I am sorry to say that these strategies seemed to be not so useful to me. I guess, I might be born to be nervous. (Example 14)

Both the quantitative results and the qualitative findings as reported in this section indicate that the strategies indentified in Stage I are basically effective in reducing students' FLSA. Overall, the participants in the experimental groups demonstrated significantly lower FLSA levels than their counterparts in the control groups after a period of four months' application of coping strategies. The present study suggests that with long term utilisation of effective strategies, students are very likely to be able to cope with their FLSA efficiently, which will help to form a conducive environment for them to enjoy FL learning.

\section{Discussion}

The goal of this study was to suggest some effective strategies to alleviate students' FLSA. Through a combination of qualitative and quantitative methods, 32 such strategies were identified (see Appendix II). Although they cannot solve the issue of FLSA once and for all, the emphasis is on the persistent application of the verified strategies by EFL learners and teachers in bilingual education in China. Among these strategies, the first 12 were derived from the questionnaire survey, the other 20 from interviews. Actually, Strategies 1, 2, 3, 5, 6, 7, and 10 were also mentioned in interview data. In other words, the two research methods cross-validated each other. It is worth noting that some of the strategies are centred on EFL teachers' characteristics and behaviours. Teachers are supposed to play a key role in alleviating students' FLSA since teachers are believed to be a key player in students' FLA (Alrabai 2014a; Shabani 2012). For example, EFL teachers' beliefs (e.g. every error should be corrected) about language teaching and the teaching methods (e.g. teachers provide little chance for students to talk in class) they employ are all among the major reasons leading to students' FLA.

With regard to EFL teachers' personal characteristics, being humourous was found to be a very effective strategy coping with students' FLSA according to the findings in the present study. Humour is important in foreign language teaching for at least two reasons. Firstly, students are potentially exposed to a relatively high level of anxiety when learning another language (Horwitz 1986; Maclntyre and Gardner 1989; Young 1991); while humour (especially teacher's humour) can help reduce students' anxiety and stimulate their desire to participate in speaking activities by creating a relaxing classroom atmosphere (Wagner and Urios-Aparisi 2008). Such a low affective filter is conducive to high motivation and self-confidence in FL learning (Krashen 1982). Secondly, humour can facilitate the acquisition of the content ideas of the target language and culture by providing an 'instrument for cultural and social transmission' (Alexander 1997, p. 7) and increasing 'retention of the input' (Ziyaeemehr, Kumar, and Abdullah 2011, p. 116). The more content ideas they get to know about the target 
language and culture, the better they will communicate in the target language, and the less FLSA they will experience. This might imply that teachers as well as students themselves should enhance their awareness of making good use of humour in daily FL teaching and learning in order to relieve students' FLSA.

Another effective strategy in reducing students' FLSA is to have a patient teacher in the classroom. Teachers' patience is acknowledged to be an important personal quality when coping with students' anxiety (Alrabai 2014b). It is unavoidable for students to make mistakes when they are struggling to express themselves in a language not their own. Hence teachers should be tolerant to students' small errors that do not affect the communication process, which will release pressure and strengthen students' selfconfidence. In the classroom, FL teachers should not only encourage students' active participation but also show patience to students' silence when they are not supposed to. Studies (e.g. Du 2009) prove that there is little use pushing or forcing students to say something when they are unwilling or not ready to say; on the contrary, it can only make them more anxious. Therefore, giving students enough 'think time' is necessary. However, this may raise another issue as many teachers feel time constraints in getting through a syllabus. A balance of moving through the syllabus and allowing enough 'think time' needs to be achieved.

Similar to Alrabai (2012) and Young (1990), the present study also found that having students work in pairs or small groups help reduce their FLSA since they tend to feel safe in groups and are usually more eager to participate in speaking activities in small groups, and group work enhances cooperation among students as well. After group discussions, students can rejoin the whole class to share their group debates with others. It deserves noticing, however, that teachers should make sure that a sense of small community should be created in the groups, or else, students might feel competitiveness and peer pressure in groups. In addition, teachers should try to make groups formed with mixed ability students, to challenge groups with academically equal tasks, and to use the same questioning strategies for all groups so that the learners would not feel that they are treated differently with respect to their foreign language proficiency (Alderman 2008).

It is argued that a stressful classroom atmosphere works as an affective filter preventing easy acquisition and restricting learners from taking in and processing incoming information (Krashen 1985). On the contrary, a friendly, relaxing and supportive learning environment is acknowledged to be able to decrease learners' anxiety (Alrabai 2014a). What is found in this study supports these arguments. The present data also suggest that a friendly classroom environment requires the efforts from both the teacher and students. On the one hand, the teacher should be friendly and try to create a low-anxiety classroom. On the other hand, students should also be friendly to one another and try not to exert unnecessary peer pressure on others. In this way, students would feel encouraged to take part in oral activities without constantly 
worrying about being negatively evaluated.

The present study indicates that being well-prepared before speaking can also reduce FLSA quite effectively. FL learners can get prepared for speaking at different levels. At the general level, they can get better equipped by continuously improving their overall FL proficiency, so they would be less anxious while speaking. Specifically, if they are preparing for a public speech or a contest in a FL, they can practise speaking and reading in front of a mirror at home. In this way, they will see themselves as others see them, and they will gain confidence to speak the FL since they have realised that they do not look different or weird in the process.

\section{Conclusion}

This study has found a comparatively high level of FLSA among Chinese bilingual students, which is a very important reason for their less-than-satisfactory EFL learning achievements. Therefore, it is of significance to investigate the strategies helping reduce their FLSA. However, most of them have seldom thought about how to reduce anxiety and many of the teachers are not equipped with awareness and understanding of FLSA and its coping strategies. A possible reason is that FLSA has not been much studied or discussed and has not caught much attention from EFL teachers and learners alike in China.

In spite of the fact that 'English Teaching Methods' is suggested as an elective for English majors by the Ministry of Education in China, only a few universities offer such a course (He 2011). However, a number of these English majors will be English teachers in China after graduation. Even for the universities that offer such a course, none of the nine textbooks and reference books they are using includes the content about how to deal with students' FLA, especially FLSA. Consequently, the effective 32 strategies reported and verified in this study contribute greatly to FLSA research as well as EFL teaching and learning in China considering that Chinese students are experiencing a comparatively high level of FLSA.

Previous studies on FLSA provided insights mainly from students' perspective, the present study has offered insights from both teachers' and students' perspectives, which will contribute to a growing literature on FLSA. The insights and beliefs from both parties will generate valuable pedagogic implications for Chinese students' English learning, especially the non-English majors' oral English acquisition. Both teachers and students should enhance their awareness and mastery of the strategies concerning FLSA management so as to effectively reduce FLSA. In so doing, systematic training programmes and tutorial workshops on FLSA should be developed and carried out in an on-going process. Hopefully the findings of the present study can provide EFL teachers and students with a baseline for their remedial action.

Practically, the strategies identified may be applied to not only EFL students in mainland China but also Chinese students learning EFL/ESL in Hong Kong, Macao, 
Taiwan, and Singapore, since they share the same mother language and learning culture. With the strategies provided by this study as important references, prospective and in-service EFL/ESL teachers in these regions/country will be able to ease their students' FLSA, and students themselves can learn oral English free from unnecessary affective barriers.

Severe FLSA decreases the probability of achieving a high degree of spoken proficiency in the target language and may cause other related problems, such as lowering self-esteem, reducing self-confidence in target language learning, and lessening willingness to take risks (Crookall and Oxford 1991), whereas a lower level of anxiety is likely to improve language acquisition, retention and learning motivation (e.g. Alrabai 2014a; Young 1990). Different students may be responsive to different coping strategies. Tertiary EFL teachers in China are strongly recommended to work out the most appropriate management strategies for students in order to enhance their learning efficiency and promote the development of bilingual education in the long run. One direction for future research in this area would be further verification of the strategies reported in this study by comparing the learning achievements of experimental and control groups, which would be another longitudinal investigation and is beyond the scope of the present study. 


\section{Appendix I}

Questionnaire I

Please circle the option that best matches your feeling about each statement. There are no right or wrong options, all depending on your first reaction. The options stand for:

$\mathrm{SD}=$ strongly disagree, $\mathrm{D}=$ disagree, $\mathrm{N}=$ neither agree nor disagree, $\mathrm{A}=$ agree, $\mathrm{SA}=$ strongly agree.

1. I feel embarrassed to speak English because I think I have poor pronunciation and intonation.
SD
D N
A
SA

2. I am often worried that if I cannot speak English well I will not get a decent job in future.
SD
D $\quad \mathrm{N}$
A
SA

3. I feel that not knowing enough vocabulary is the biggest problem preventing me from speaking a foreign language easily.
SD
$\mathrm{N}$
A
SA

4. I become anxious when I get stuck on one or two words in speaking a foreign language.
SD
D N
A
SA

5. I feel more nervous when having to give important information orally in a foreign language.
SD
$\mathrm{N}$
A
SA

6. I would not be so anxious just to learn to read and write in a foreign language rather than having to learn to speak as well.
SD
D N
A
SA

7. I do not mind thinking aloud in a foreign language, but I feel very uncomfortable when I have to speak to others in it.
SD
$\mathrm{N}$
A
SA

8. I am nervous if I have to speak a foreign language when I am not familiar with the topic.
SD
D $\quad \mathrm{N}$
A
SA

9. When speaking a foreign language, I often know all the words I need but still fail to express myself easily due to nervousness.
SD
$\mathrm{N}$
A
SA

10. I feel nervous when having to be tested orally in a foreign language.
SD
D $\quad \mathrm{N}$
A
SA

11. I get worried when I have little time to think about what I have to speak in a foreign language.
SD
D N
A
SA

12. I get anxious when I find I cannot speak in the foreign language fluently.
SD
$\mathrm{D} \quad \mathrm{N}$
A
SA

13. Others will look down on me if I make mistakes in speaking a foreign language.

SD

D $\quad \mathrm{N} \quad \mathrm{A} \quad \mathrm{SA}$




\section{Appendix II}

The list of the strategies identified in stage I:

1. Teacher trying to be humourous;

2. Speaking a FL in a friendly environment;

3. Teacher trying to be patient;

4. Not focusing on accuracy while speaking a FL;

5. Teacher trying to be encouraging;

6. Correcting mistakes indirectly;

7. Knowing that mistakes are part of the FL learning process and made by everyone;

8. Having classmates work in small groups;

9. Playing language games;

10. Doing relaxation exercises;

11. Participating in a supporting group or activity;

12. Talking with other students about the fears of speaking a FL;

13. Trying to use a FL more;

14. Preparing well before FL classes;

15. Providing examples before oral tasks;

16. Using more body language to help express oneself;

17. Overcoming the reasons leading to anxiety;

18. Being brave to speak a FL;

19. Trying to use simple words while speaking a FL;

20. Watching some real life TV programmes in a FL;

21. Teacher trying to be knowledgeable;

22. Good at enhancing students' interest in a FL;

23. Good at employing different teaching strategies;

24. Teacher trying to be lively;

25. Teacher trying to be good at creating conducive learning environment;

26. Teacher trying to be modern (instead of being reserved);

27. Teacher trying to be outgoing;

28. Teacher trying to be versatile;

29. Sensitive to cultural differences;

30. Excluding students' classroom performance from final assessment;

31. Learning some teaching styles from native-speaking English teachers;

32. Teacher trying to be easy-going. 


\section{Appendix III}

One classroom observation log for the application of the anxiety coping strategies.

\begin{tabular}{ll}
\hline Minutes & Strategies applied \\
\hline 1 & $\begin{array}{l}\text { The teacher began the class with a joke related to } \\
\text { the topic of the lecture. }\end{array}$ \\
$4-20$ & $\begin{array}{l}\text { Students discussed the task assigned (online } \\
\text { shopping experience) in groups of } 4-5 \text { and then one }\end{array}$ \\
& student from 6 of the groups reported to the class.
\end{tabular}

10 One student said 'he like buying food online'. The teacher did not correct the student directly, instead, she repeated 'Good. He likes buying food, right? Anything else?'.

16 One student seemed to be blocked when she tried to say the word 'procrastinate'. The teacher spelled the word on the board and said 'We can also say it simply here, like "keep delaying"'.

21-30 The teacher explained 'nominalisation' and its usage to students with the following as one of the examples: 'The sentence he succeeded in online games, and this brought him money and fame can be rephrased as his success in online games brought him money and fame'.

28-30 One student had some trouble while making a sentence with 'communicate' and then rewording it with 'communication', but the teacher showed her patience and joked 'Don't worry. This is not a test, and you won't be given a mark for it'.

31-50 In the following 20 minutes, the class learnt a short passage together. The teacher demonstrated her knowledge and her outgoing and lively characteristics.

The effects of the strategy

The students laughed and seemed to be relaxed because of the joke. The students seemed to be wellprepared when reporting their discussion. Their familiarity with this topic made their speeches fluid and vivid.

The student realised the error and repeated the sentence correctly and went on with his speech.

The student nodded and said 'Yes. I mean delay'. Then she went on saying more about her experience.

Then several students learnt to paraphrase sentences with 'failure', 'disappearance', and 'communication' instead of 'fail', 'disappear', and 'communicate' respectively.

The student smiled and tried again, and finally got both sentences correct.

The students seemed to be impressed and attracted by the teacher and also to be at ease with the learning.

Note: All the 'seemed to be' were confirmed to be true in the talks with students after class. 


\section{References}

Alderman, M.K. 2008. Motivation for achievement: Possibilities for teaching and learning (3rd ed.). New York: Routledge.

Alexander, R.J. 1997. Aspects of verbal humour in English. Tübingen: Gunter Narr Verlag.

Alpert, R., and R.N. Haber. 1960. Anxiety in academic achievement situations. Journal of Abnormal and Social Psychology 61(2): 207-215.

Alrabai, F. 2012. Saudi EFL teachers' and students' perceptions of motivational strategies. Papers from the Lancaster University Postgraduate Conference in Linguistics and Language Teaching 2012. Retrieved from: http://www.ling.lancs.ac.uk/pgconference/v07/Eman.pdf (December 2014)

Alrabai, F. 2014a. A model of foreign language anxiety in the Saudi EFL context. English Language Teaching 7: 82-101.

Alrabai, F. 2014b. The influence of teachers' anxiety-reducing strategies on learners' foreign language anxiety. Innovation in Language Learning and Teaching 8: 1-28.

Brown, J.D., and T.S. Rogers. 2002. Doing second language research. Oxford: Oxford University Press.

Crookall, D., and R.L. Oxford. 1991. Dealing with anxiety: Some practical activities for language learners and teacher trainees. In Language anxiety: From theory and research to classroom implications, eds. E.K. Horwitz and D.J. Young, 140-150. Englewood Cliffs: Prentice Hall.

DeVellis, R.F. 1991. Scale development: Theory and applications. CA: Sage.

Dewaele, J-M. 2013. Emotions in multiple languages (2nd ed.). Basingstoke: Palgrave Macmillan.

Donley, P.M. 1997. Ten ways to cope with foreign language anxiety. Mosaic: A Journal for the Interdisciplinary Study of Literature 30: 17.

Du, X. 2009. The affective filter in second language teaching. Asian Social Science 5: 162-165.

Gable, R.K., and M.B. Wolf. 1993. Instrument development in the affective domain: Measuring attitudes and values in corporate and school settings. Boston: Kluwer-Nijhoff.

Gardner, R.C., and P.D. Maclntyre. 1993. On the measurement of affective variables in second language learning. Language Learning 43(2): 157-194.

Gregersen, T.S. 2003. To err is human: A reminder to teachers of language-anxious students. Foreign Language Annals 36: 25-32.

Gregersen, T.S., and E.K. Horwitz. 2002. Language learning and perfectionism: Anxious and non-anxious language learners' reactions to their own oral performance. The Modern Language Journal 86: 562-570.

Hashemi, M., and M. Abbasi. 2013. The role of the teacher in alleviating anxiety in language classes. International Research Journal of Applied and Basic Sciences 4: 640-646.

He, D. 2011. Foreign language speaking anxiety: An investigation of non-English majors in mainland China. Unpublished PhD dissertation, City University of Hong Kong, Hong Kong.

He, D. 2013. What makes learners anxious while speaking English: A comparative study of the perceptions held by university students and teachers in China. Educational Studies 39: 338-350.

He, D. (2015). University students' and teachers' perceptions of China English and world Englishes: Language attitudes and pedagogic implications. Asian Journal of Applied Linguistics. 2(2), 65-76.

He, D., \& Zhang, Q. (2010). Native speaker norms and China English: From the perspective of learners and teachers in China. TESOL Quarterly, 44(4), 769-789.

Horwitz, E.K. 1986. Preliminary evidence for the reliability and validity of a foreign language anxiety scale. TESOL Quarterly 20: 559-562. 
Horwitz, E.K., M.B. Horwitz, and J. Cope. 1986. Foreign language classroom anxiety. The Modern Language Journal 70: 125-132.

Kim, J.-h. 2000. Foreign language listening anxiety: A study of Korean students learning English. Unpublished PhD dissertation, the University of Texas at Austin, Austin, the USA.

Kondo, D.S., and Y.-L. Yang. 2004. Strategies for coping with language anxiety: The case of students of English in Japan. ELT Journal 58: 258-265.

Krashen, S.D. 1982. Principles and practice in second language acquisition. Oxford: Pergamon Press.

Krashen, S.D. 1985. The input hypothesis: Issues and implications. London: Longman.

Liu, M. 2007. Anxiety in oral English classrooms: A case study in China. Indonesian Journal of English Language Teaching 3: 119-137.

Liu, M., and J. Jackson. 2008. An exploration of Chinese EFL learners' unwillingness to communicate and foreign language anxiety. The Modern Language Journal 92: 71-86.

Lucas, J. 1984. Communication apprehension in the ESL classroom: Getting our students to talk. Foreign Language Annals 17: 593-598.

Maclntyre, P.D., and R.C. Gardner. 1989. Anxiety and second-language learning: towards a theoretical clarification. Language Learning 39: 251-275.

MacIntyre, P.D., K.A. Noels., and R. Clément. 1997. Biases in self-ratings of second language proficiency: The role of language anxiety. Language Learning 47: 265-287.

Ministry of Education. 2014. Educational statistics in 2014. Retrieved from: http://www.moe.gov.cn/s78/A03/moe_560/jytjsj_2014/2014_qg/201509/t20150902_205106.html (September 2015).

Onwuegbuzie, A.J., P. Bailey, and C.E. Daley. 1999. Factors associated with foreign language anxiety. Applied Psycholinguistics 20: 217-239.

Shabani, M.B. 2012. Levels and sources of language anxiety and fear of negative evaluation among Iranian EFL learners. Theory and Practice in Language Studies 2: 2378-2383.

Spielberger, C.D. 1983. Manual for the state-trait anxiety inventory (Form Y). Palo Alto, CA: Consulting Psychologists Press.

Wagner, M., and E. Urios-Aparisi. 2008. Pragmatics of humour in the foreign language classroom: Learning (with) humour. In Developing contrastive pragmatics: Interlanguage and cross-cultural perspectives, eds. M. Putz and J.N.-v. Aertselaer, 209-228. New York: Mouton de Gruyter.

Yan, J.X., and E.K. Horwitz. 2008. Learners' perceptions of how anxiety interacts with personal and instructional factors to influence their achievement in English: A qualitative analysis of EFL learners in China. Language Learning 58: 151-183.

Young, D.J. 1990. An investigation of students' perspectives on anxiety and speaking. Foreign Language Annals 23: 539-553.

Young, D.J. 1991. Creating a low-anxiety classroom environment: What does language anxiety research suggest? The Modern Language Journal 75: 426-439.

Young, D.J. 1992. Language anxiety from the foreign language specialist's perspective: Interviews with Krashen, Omaggio Hadley, Terrell, and Rardin. Foreign Language Annals 25: 157-172.

Ziyaeemehr, A., V. Kumar, and M.S.F. Abdullah. 2011. Use and non-use of humour in academic ESL classrooms. English Language Teaching 4: 111-119. 